\title{
Embedding Teacher Professional Learning into the Student-Focused GEAR UP Engineering Summer Camp (Evaluation)
}

\section{Ryan Barlow, Utah State University}

Ryan Barlow obtained his Bachelor's Degree in Mechanical Engineering from the University of Utah in 2012 and his Master's Degree in Science Education from the University of Maryland in 2016. He is currently a PhD candidate in Engineering Education at Utah State University where his research focuses on continuing professional development of engineering educators.

\section{Dr. Max L Longhurst, Utah State University}

Dr. Longhurst is an Assistant Professor of Science Education in the School of Teacher Education and Leadership at Utah State University. His research focuses on the appropriation of professional learning in science education. Heholds a Ph.D. in Curriculum and instruction from Utah State University (2015), a Masters Degree in Instruction and Curriculum from Arizona State University (1995), a Bachelor of Science in Elementary Education from Brigham Young University(1993). Dr. Longhurst has directed local and large scale professional development programs providing instructional learning experiences involving over 4,000 elementary teachers annually. Currently he coordinates the Elementary STEM Endorsement program at Utah State University.

\section{Prof. Kurt Henry Becker, Utah State University - Engineering Education}

Kurt Becker is the current director for the Center for Engineering Education Research (CEER) which examines innovative and effective engineering education practices as well as classroom technologies that advance learning and teaching in engineering. He is also working on National Science Foundation (NSF) funded projects exploring engineering design thinking. His areas of research include engineering design thinking, adult learning cognition, engineering education professional development and technical training. He has extensive international experience working on technical training and engineering educaton projects funded by the Asian Development Bank, World Bank, and U.S. Department of Labor, USAID. Countries where he has worked include Armenia, Bangladesh, Bulgaria, China, Macedonia, Poland, Romania, and Thailand. In addition, he teaches undergraduate and graduate courses for the Department of Engineering Education at Utah State University. 
Embedding Teacher Professional Learning into the StudentFocused GEAR UP Engineering Summer Camp (Evaluation) 


\title{
Embedding Teacher Professional Learning into the Student-Focused GEAR UP Engineering Summer Camp (Evaluation)
}

\begin{abstract}
The Gaining Early Awareness and Readiness for Undergraduate Programs (GEAR UP) grant, from the Department of Education, addresses the need for more students in STEM disciplines by focusing on increasing student interest in STEM fields. As a part of the Science, Technology, Arithmetic, Reading Students (STARS!) project, students and teachers from school districts throughout the mountain west region, participated in the GEAR UP Engineering Summer Camp 2019 at a university in the mountain west region. The engineering camp targeted 6 th to 12 th grade underrepresented students and STEM teachers from the participating schools. During the 2019 camp, students and teachers worked in teams to perform real-world engineering research investigations in collaboration with engineering research faculty at a university in the mountain west region. The camp focused on the interaction of urban and natural areas, and their effect on water quality and air quality in the local environment. Although the main purpose of the camp was to increase interest in and knowledge about engineering in middle-school and high school students in the mountain west region, the camp provided an opportunity to work with the participating teachers and develop their understanding of the recently approved Science with Engineering Education (SEEd) Standards for K-12 and the Framework for K-12 Science Education. Teachers are facing challenges in incorporating these standards in their curriculum. Rather than have the teachers serve only as chaperones for the students, this years' camp served as a professional learning experience for the seven participating STEM teachers. Throughout the camp, the STEM teachers participated in authentic engineering experiences with their students and engaged in professional learning discourse about three-dimensional science instruction and the camp experience. They also participated in engineering education workshops led by the researchers, which included discussion about the SEEd Standards and the Framework, engineering design activities, and collaborative work sessions to plan a lesson related to engineering implementation in their own classroom. The main purpose of the teacher professional learning was to help the participating STEM teachers incorporate the recommendations from the framework for K-12 science education and the SEEd Standards. During the academic year following the camp, the researchers observed the participating teachers in their own classrooms teaching the lesson plans that they created during the camp. The researchers also conducted two semi-structured interviews with the teachers, one at the end of the camp which focused on the teachers experiences at the GEAR UP Engineering Camp and the second in their own classrooms immediately following the observed lesson which focused on the implementation of what they had learned in the professional learning experience. The qualitative data obtained from the observations and the interviews allow the researchers to evaluate the combination of a teacher professional learning experience with a student-focused engineering summer camp. The data also determines if the professional learning experience helped the teachers to better implement the Framework for K-12 Science Education and the SEEd Standards in their own STEM classes.
\end{abstract}

\section{Introduction}

In June 2019, the Utah State Board of Education approved the new Utah Science with Engineering Education (SEEd) Standards [1], which came as a result of the Next Generation 
Science Standards (NGSS) and the Framework for K-12 Science Education [2]. These standards include the expectation that K-12 science teachers in the state of Utah incorporate engineering into their science classes. Studies show that many teachers have struggled to accomplish this [3] [4] [5]. There are several possible reasons for these struggles. The results of one study show that many science teachers do not have a sufficient understanding of engineering concepts [6]. Other studies show that K-12 science teachers often do not have any background in engineering [7]. Another possible reason for the difficulties that teachers have had in incorporating engineering into their science classes is that many teachers lack self-efficacy in teaching engineering [5] [8] [9]. In order for teachers to overcome these challenges, there is a need for improved professional learning opportunities for science teachers focused on teaching engineering.

There is a significant push for such professional learning opportunities for K-12 science teachers across the country. At the 2019 Annual Conference \& Exposition of the American Society for Engineering Education, there were several presentations and posters related to engineering professional development programs for K-12 science teachers. Some of these programs were more traditional professional development programs where teachers came and learned from engineering education experts [10] [11]. Participants in these programs were then expected to teach either a similar program to other teachers after further training [10] or to lead an informal STEM program for students [11]. Another program was geared towards pre-service teachers and involved learning about engineering design and completing a team design project [12]. Multiple programs allowed teachers to participate in engineering research with engineering faculty and students [13] [14] [15] [16]. While participating in many of these programs, the teachers were expected to create lesson plans related to engineering [12] [13] [14] [16]. In addition to all these presentations, the results of the initial pilot study of this research was presented as a work in progress at the Conference.

These professional development programs all involved helping K-12 teachers to apply engineering in their science classrooms. But in these programs, the teachers participated in the professional development and then returned to their classrooms where students became involved in the process. This research focuses on combining the student-focused experience in an engineering summer camp with a teacher-focused experience. Student engineering camps have been running for several years, including the camp that is the focus of this research. But the research on these engineering camps is focused on engineering outreach to students and the effect that the engineering camps have on students' perceptions and attitudes towards, and interest in, engineering [17] [18] [19] [20] [21].

During the summer of 2019, teachers and students from districts in the state of Utah and one district in the state of Nevada participated an Engineering Summer Camp on the campus of a university in the mountain west region. This camp was funded by a Gaining Early Awareness and Readiness for Undergraduate Programs (GEAR UP) grant and was a part of the Science, Technology, Arithmetic, Reading Students (STARS!) program at a university in the mountain west region. The 2019 Engineering Camp was targeted towards students entering the $11^{\text {th }}$ grade as well as teachers from the participating schools. During the week-long Engineering Camp, teachers and students participated in engineering activities led by engineering faculty and students. These activities included using Remotely Operated Vehicles (ROV) submarines to 
collect data on water quality, using other methods for collecting water data, collecting air quality data using sensors, and flying small drones.

In addition to participating in the engineering activities with the students, the teachers were able to participate in professional development workshops led by a science education faculty member with expertise in teacher professional development and an engineering education graduate student. During these workshops, the teachers were introduced to the new Utah SEEd Standards and participated in discussions and a hypothetical design problem activity related to the Science and Engineering Practices (SEPs) in the Framework for K-12 Science Education [2] and the Engineering Design Process. The teachers were then given time to craft a series of engineering related lesson plans. The engineering activities, combined with the professional development workshops, created the professional learning experience for the GEAR UP Engineering Summer Camp.

\section{Participants}

A total of eight STEM teachers participated in the GEAR UP Engineering Camp professional learning experience. Of these eight teachers, one was still in school and was not yet in their own classroom, one was about to begin teaching at a middle school, and the other six were high school teachers. Of the seven teachers who already were or were about to be in the classroom, two were math teachers, one was an engineering teacher, and the other four were science teachers. There were four female teachers and four male teachers. One of the teachers was from a school district in the state of Nevada and the others were from five different school districts in the state of Utah. The number of years of teaching experience for the teachers ranged from 0 (for the first-year teacher) to 6 years. The subjects that are taught by the participating STEM teachers include: Math, Physics, Chemistry, Physical Science, Biology, and Engineering.

Three of the participating teachers had previous knowledge of the Next Generation Science Standards (NGSS) and one teacher was already familiar with the Utah SEEd Standards. The same three teachers had tried to implement the Science and Engineering Practices (SEPs) in their classroom. Two of these three teachers had participated in the GEAR UP Engineering Camp in 2018 including the engineering experiences and the professional development workshop and the third teacher had taken a class in which the NGSS, the Utah SEEd Standards, and the Science and Engineering Practices (SEPs) were discussed.

\section{Program Description}

For one week in July 2019, eight STEM teachers participated in the GEAR UP Engineering Camp professional learning experience. The primary purpose of the camp for the teachers was to help them to incorporate engineering into their STEM classes. This was done through having the teachers participate alongside students from their schools in authentic engineering experiences. For these engineering experiences, the teachers and students were divided into four groups. Each of these four groups rotated through four different engineering experiences led by engineering faculty and students according to the schedule as shown in Figure 1. Each group spent approximately four hours on each activity during the second and third days of the camp. These engineering experiences included: using simple ROV submarines to collect underwater data, 
colleting data in streams, using drones and sensors to collect air quality data, and flying drones using a computer simulation and with actual drones.

\begin{tabular}{|c|c|c|c|c|c|c|c|c|c|c|c|}
\hline \multicolumn{12}{|c|}{ GEARUP Engineering Summer Program 2019} \\
\hline \multicolumn{12}{|c|}{ Dates: July 8 - 12, 2019} \\
\hline & Monday & \multicolumn{4}{|c|}{ Tuesday } & \multicolumn{4}{|c|}{ Wednesday } & \multirow{2}{*}{$\begin{array}{c}\text { Thursday } \\
8 \text { to } 5\end{array}$} & \multirow{2}{*}{$\begin{array}{l}\text { Friday } \\
8 \text { to } 12\end{array}$} \\
\hline Teams and Topics & 1 to 4 & \multicolumn{2}{|c|}{8 to 12} & \multicolumn{2}{|c|}{1 to 5} & \multicolumn{2}{|c|}{8 to 12} & \multicolumn{2}{|c|}{1 to 5} & & \\
\hline Overview of Program (all) & $*$ & & & & & & & & & & \\
\hline Assemble Sea Perch Subs (all) & $*$ & & & & & & & & & & \\
\hline Student Team \#1 & & 1 & 1 & 2 & 2 & 3 & 3 & 4 & 4 & Team 1 -Reseach & Poster Session \\
\hline Student Team \#2 & & 2 & 2 & 1 & 1 & 4 & 4 & 3 & 3 & Team 2 -Res each & Poster Session \\
\hline Student Team \#3 & & 3 & 3 & 4 & 4 & 1 & 1 & 2 & 2 & Team 3 -Reseach & Poster Session \\
\hline \multirow[t]{2}{*}{ Student Team \#4 } & & 4 & 4 & 3 & 3 & 2 & 2 & 1 & 1 & Team 4 -Reseach & Poster Session \\
\hline & All & \multicolumn{9}{|c|}{ Team Activities } & All \\
\hline Air Quality / Drones & \multicolumn{11}{|c|}{ drones, vert. profiles, temp. profiles } \\
\hline AggieAir & \multicolumn{11}{|c|}{ aircraft data collection \& payloads } \\
\hline Sea Perch Submarines & \multicolumn{11}{|c|}{ robots collect stream data } \\
\hline GIS Stream Data & \multicolumn{11}{|c|}{ stream data along the watershed } \\
\hline
\end{tabular}

Figure 1: GEAR UP Engineering Camp Group Division and Schedule

After participating in all four of the activities, the teachers and students were able to individually select their top choices for which activity on which they wanted to go more in depth. The researchers placed the teachers and students into four different groups based on their top choices. On the fourth day of the camp these groups spent eight hours going more in depth into the four different engineering experiences, including data collection and analysis. This more in-depth investigation was centered around research questions that each group of students and teachers had formulated. That evening, the student groups, with help from the teachers, created posters about the research questions, the data collection, and data analysis. On the morning of the fifth day of the camp, the students presented these posters to engineering students, faculty, and any others interested in the results.

\section{Engineering Experiences}

\section{$\underline{\text { Sea Perch ROV Submarines }}$}

On the first day of the camp, the teachers and students assembled Sea Perch ROV Submarines from kits that were provided, under the supervision of the engineering faculty member and engineering students that were leading this engineering experience. On the subsequent days, the teacher and student groups used their Sea Perch ROV submarines in a small local reservoir. First, the students and teachers used small bags of pebbles to provide enough weight for the submarines to sink and to provide balance under the water. After making sure that the submarines were stable, and that they were able to steer the submarines, the students and 
teachers collected data using the sensors on the subs, and collected water samples. The groups then looked at the data and make sure that they were able to get good data. The students and teachers then took the submarines back to the water to take pictures and video that they could use for their posters if they chose to participate in this activity on the fourth day of the camp. The groups finished early at the reservoir and returned to campus to begin to analyze the data on the computer with the help of the engineering faculty and students.

On the fourth day of the camp, the students and teachers who chose to participate in this engineering experience went to a deeper reservoir that was a little further from the campus, went out into small boats, and collected more data using the ROV submarines. After collecting enough data to answer their research questions, the teachers and students returned to campus to analyze the data and begin to work on their posters.

\section{$\underline{\text { Stream Data }}$}

On the second and third days of the camp, the groups of teachers and students went to where the local river flows into the reservoir near campus. They were divided into even smaller groups and rotated between four stations. Three of the stations involved using three different methods of measuring the flow of the river with varying levels of complexity and at different depths. At the fourth station, the students and teachers collected some small samples of water which they tested for various substances and for overall water quality.

On the fourth day of the camp, the teachers and students who had chosen this engineering experience went up into the nearby canyon and stopped at several locations along the river. At each of these stops along the river, the groups measured the flow of the stream and took additional water samples to test for water quality. After the last stop, the teachers and students returned to campus to analyze the data in a computer lab and begin to work on their posters.

\section{Air Quality}

For the Air Quality engineering experience, the teachers and students were divided into two smaller groups and rotated through two different activities. One group sat and listened to a lecture about air quality and learned about the scientific background of air quality measurements. This activity also included a demonstration of inversions. The other group went with the engineering faculty member who was leading the activity and listened to a short presentation about air pollution. The teachers and students in this group put together simple air quality sensors by following a set of printed instructions and then used the sensors to measure the air quality both indoors and outdoors in various situations including after stomping on a carpeted floor, after kicking a truck tire, a truck's exhaust, above a candle flame, above a rock crusher, and near a lit cigarette under a vent hood.

For the activities on the fourth day, the teachers and students who chose to do more in-depth work with air quality split into two different groups according to their chosen research question. One of the groups investigated the differences in the particulate readings from different flames including a burning campfire, a smoldering campfire, candles, candle warmers, burning crayons, cigarettes, and cigars. All of these, except the campfire (which was outside in a controlled 
environment), were burned under a vent hood so that the students and teachers did not breathe in the smoke. The other group used the air quality sensors to measure the particulate readings for the exhaust from different vehicles including sedans, pickup trucks, and diesel trucks. After obtaining the particulate data, both groups returned to the computer lab to analyze the data in a computer lab and begin to work on their posters.

\section{$\underline{\text { Aggie Air }}$}

In the beginning of the Aggie Air engineering experience, the teachers and students were given a tour of the shop where the Aggie Air group builds and programs drones. The professors and students in the Aggie Air group gave a presentation to the students about the projects that they do. After this presentation, the students and teachers were divided into three groups who rotated through three different activities. These activities included learning some basic programming of the drones, using an authentic flight simulator on the computer to fly simulated drones using special controllers that imitate real drone controls, and learning about safety before flying actual drones in a controlled environment.

On the fourth day, the students and teachers who chose the Aggie Air group were able to assemble small quadcopter drones from kits and fly them through a set course. They were then able to make simple modifications to the drones in order to go faster through the course. After completing the modifications, the groups prepared their posters explaining the changes they made to the drones and the results.

\section{Teacher Professional Learning Workshops}

On the first evening of the teacher professional learning workshop, three of the four engineering faculty who were leading the engineering experiences came to talk to the participating STEM teachers. The purpose of this was to help the teachers to understand what they should be doing during the engineering experiences, what questions they should be asking, and what resources would be available to them if they chose to implement any of the engineering activities in their own classes. After the engineering faculty left, the participating STEM teachers were asked to read the introduction of the Utah SEEd Standards. The two researchers who were running the professional learning workshops then led a discussion on the Utah SEEd Standards, the 3dimensions of science learning, and the Science and Engineering Practices (SEPs).

Following this discussion, the graduate student researcher introduced a team design activity. This activity involved a hypothetical design problem in which the teachers were divided into teams of two and asked to design a method of collecting samples and water quality data from the deepest point of a nearby lake. The teachers were given a list of parameters and online resources which they could use to discover the other necessary parameters and limitations for the design, such as the depth of the lake. In order to create their design, the teachers had to calculate the pressure at the deepest point of the lake. The graduate student researcher also provided a list of materials and a hypothetical cost for each material. The teachers were asked to design their method of collecting samples using these materials or other materials that they were able to find online with the approval of the graduate student researcher. The teachers were also given a specific hypothetical budget with which they could purchase materials necessary for their design. An 
additional parameter was that if they were able to spend less than the hypothetical budget, then they could hypothetically keep the surplus. The teachers were given approximately 45 minutes to complete their designs. After they completed their designs, including a description of materials and a simple drawing, the teachers were asked to present their designs to the rest of the groups.

After the completion of this design activity, the graduate student researcher led a discussion on how this simple activity included most of the SEPs from the Framework for K-12 Science Education but only took a short amount of time. This was done to show how easy it can be to include the SEPs in a lesson without having to take a field trip or purchase expensive materials. The teachers were then asked to individually create a similar hypothetical design activity that they could use in their own classes. The teachers were given approximately 20 minutes to complete this activity. The teachers then shared their design activity ideas with the rest of the group.

On the second evening of the professional learning workshop, the graduate student researcher reviewed the 8 SEPs from the Framework and introduced the teachers to a simple model of the Engineering Design Process shown in Figure 2.

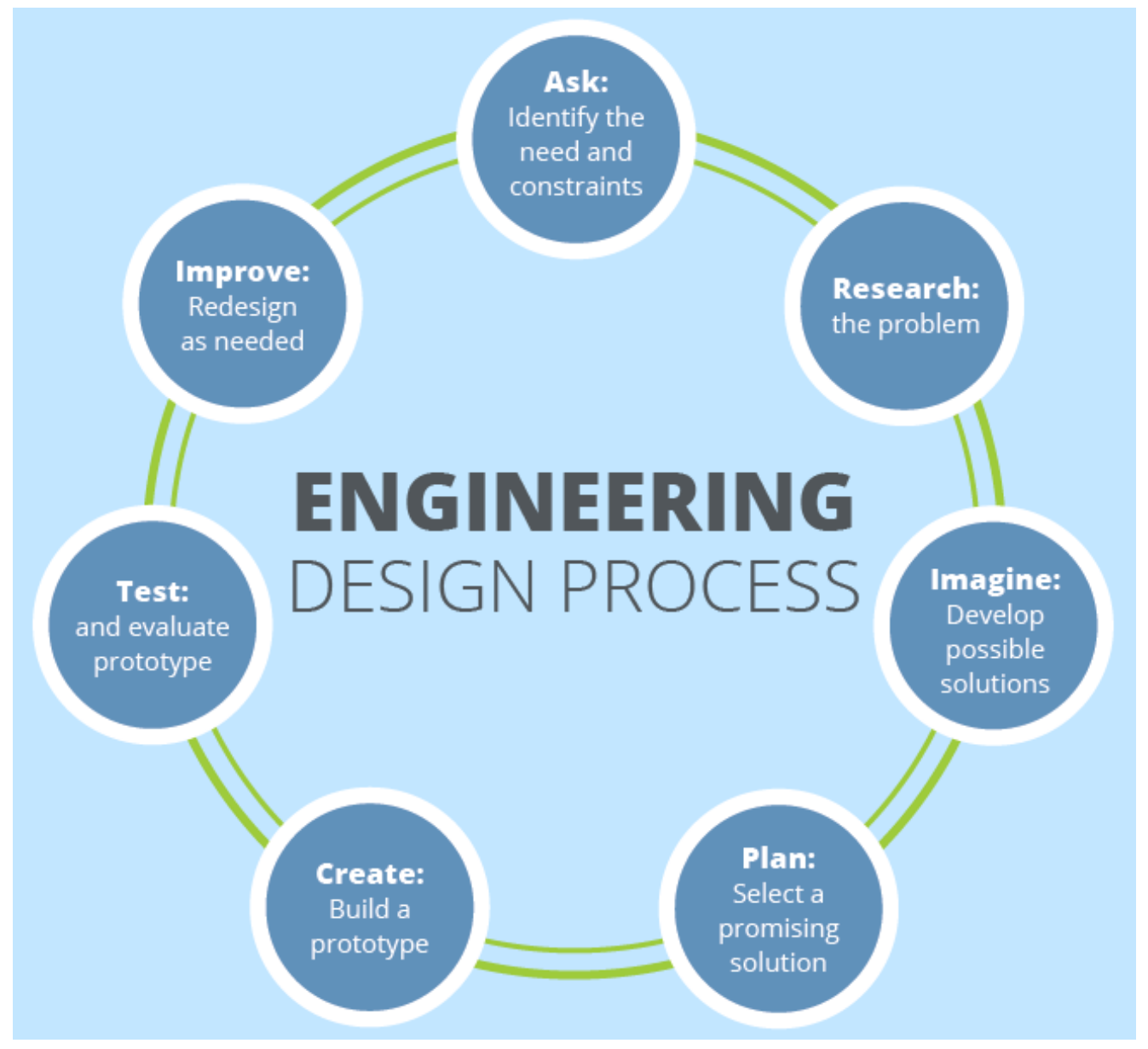

Figure 2: Simple Model of the Engineering Design Process [22] 
After introducing this simple model of the engineering design process to the participating teachers, the graduate student researcher shared several quotes from entertainment sources related to the importance of failure in the engineering design process. This was done to help the teachers to be able to help their students understand that failure is part of the engineering design process and that as long as the students learn from the failure and adapt the design, then failure is not necessarily a bad thing. The graduate student researcher then introduced the participating teachers to the resources available online to help them to craft lesson plans related to engineering. For the remainder of the time on the second evening, and the entire time on the third evening of the professional learning workshop, the teachers were given time to work individually on the series of lesson plans in which they would apply the SEPs from the Framework.

\section{Data Collection and Analysis}

In order to evaluate the success of the GEAR UP Engineering Camp professional learning experience, the graduate student researcher conducted an interview with each of the 7 STEM teachers who were, or would soon, be in the classroom. These semi-structured interviews were conducted individually with each teacher while the students were presenting their posters on the last day of the camp. The interview consisted of two questions: "Please share your thoughts about the GEAR UP Engineering Camp", and "What are your thoughts about combining professional development with the GEAR UP Engineering Camp for an overall professional learning experience?". In addition to these two questions, follow-up questions were asked based on the teachers' individual responses. The two teachers who had participated in the GEAR UP Engineering Camp the previous year were also asked "How was this camp different from last year's camp?". Most of the teachers were also asked "How was this different from other professional development programs in which you have participate?". The audio of these interviews was transcribed for the purpose of data analysis. In addition to the interview data, the graduate student researcher collected the lesson plans that the teachers created.

After the audio of the interviews was transcribed, the graduate student researcher read through all the transcriptions looking for common themes. The graduate student researcher then coded the data using in vivo coding, which is ideal for interview data because it uses the interviewees own words [23]. The engineering-related lesson plans for a series of lessons that the teachers created during the camp were analyzed by the graduate student researcher to determine how well the participating teachers were able to apply the SEPs into the lessons using the rubric in Appendix A. During the school year following the GEAR UP Engineering Camp, the teachers implemented the lesson plans in their own classrooms. The graduate student researcher observed one class period of the series of lesson plans and evaluated how well the teachers were able to apply the SEPs in the lesson using the observation protocol in Appendix B.

\section{Results}

Because the observed class period was only a portion of the series of lesson plans, it was made clear to the participating teachers that they were not expected to cover all 8 SEPs during the observed class period. Despite this, all the observed teachers except for one were able to have significant application of at least two of the SEPs during the observed lesson. When considering the series of lesson plans that the teachers created during the camp, all the teachers were able to 
have at least limited application of the majority of the eight SEPs in their lesson plans. Because two of the teachers had participated in the GEAR UP Engineering Camp during the previous year, the graduate student researcher was able to compare the lesson plan and observation data to the lesson plan and observation data from the previous year. Both teachers had improved application of the SEPs in both the lesson plan and the observed lesson.

\section{Positive Feedback}

All of the participating teachers had positive things to say about the GEAR UP Engineering Camp professional learning experience. One of the common themes among the teachers was that they enjoyed having the students experience and the teacher experience combined. One teacher said:

"I think it's effective because we can see how we might apply it with the kids are learning to our own classes, and then we have time to... think about that and actually put together lesson plans while it's fresh in our minds."

Another teacher said:

"With professional development, you talk about it, but you don't necessarily get the application part of it. Yeah, you can act it out..., but you don't really get the experience of the students until you take it back and try to implement it. This way, we got to see it firsthand and we got to... understand how the students react. We got to see the pros and cons right away."

One of the other teachers talked more about the seeing "what the students are actually getting out of it."

Several of the teachers spoke about how much they enjoyed being able to participate in the engineering experiences. One of the participating teachers enjoyed the experience of being "outside of a classroom setting and more like out in the field." Another teacher enjoyed the opportunity to "think of how to utilize the things that we're learning in the camp and apply them to the classroom." One of the other teachers reported that during the engineering experiences he "was trying to think about like what I would try to do with my class if I was doing like the same thing."

The two teachers who had participated in the GEAR UP Engineering Camp the previous year as well both reported that there had been significant improvements in some of the engineering experiences and in the professional learning workshops. Both of these teachers enjoyed having more time to work on lesson plans because they only had about an hour to work on the lesson plans the previous year. However, both teachers thought that we might have gone too far and allowed for too much time to work on the lesson plans.

The teachers' lesson plans showed that they were able to incorporate, on at least some level, the SEPs into their lessons. For the two teachers who had participated previously, the graduate student was able to compare the lesson plans submitted after the 2018 camp to the lesson plans 
submitted during the 2019 camp. In both cases, the teachers were better able to incorporate more of the SEPs into their lessons than in the previous year. One of these two teachers reported that he was able to understand the Utah SEEd Standards and the SEPs much better from this camp than the previous camp.

\section{$\underline{\text { Suggestions from Participating Teachers }}$}

There were several suggestions from the teachers about how we can improve the engineering experiences and the professional learning workshops in the future. Almost all of the teachers said that there should have been more time for the teachers to collaborate with each other instead of being given so much time to work individually on the lesson plans. Several teachers also mentioned that the researchers were expecting too much of the teachers to create basically an entire unit's worth of lesson plans. The main suggestion from the teachers was to allow them to collaborate with the other teachers at the camp while working on one or two lesson plans rather than an entire unit. One teacher suggested that the engineering faculty leading the activities could come to the professional learning workshop and explain how they do hands-on projects in their own classes.

Several teachers suggested that the engineering experiences needed to be more hands-on, particularly with the data analysis. The data analysis for several of the engineering activities was done by the professor with the students following along. The data was also too complex for many of the high school students to understand. Several teachers also suggested that the programming portion of the Aggie Air experience could allow the students to do some simple coding.

\section{Conclusions}

All the collected data shows that combining the teacher professional learning workshops with a student-centered engineering camp was a positive experience for the teachers. The teachers were able to see engineering being taught to their students with hands-on activities that they could potentially use in their own classes. The teachers were also able to gain a better understanding of engineering and how to teach it by participating in the engineering experiences with their students.

The evening professional learning workshops also helped the teachers to apply engineering in their classrooms by giving them a better understanding of the Utah SEEd Standards, the Science and Engineering Practices, and the Engineering Design Process. The teachers also benefitted from doing the hypothetical design problem. It allowed them to see that they can teach engineering without having to take up too much class time, go on field trips outside of school, or spend extra money on costly materials. One of the lesson plans from the teachers followed this format and did not have the students build a physical prototype. Several other teachers said that they would implement similar hypothetical design problems in their own classes.

\section{Broader Implications}


The partnership between practicing high school teachers, student participants and engineering faculty was important to the success of the engineering camp. Embedding teacher professional learning into the student-focused engineering summer camp reveals the benefits of collaborative efforts between K-12 educators and engineering professionals. Although the extent to which embedded teacher professional learning impacted learning outcomes was not measured, the diverse backgrounds of the camp facilitators allowed for the combination of pedagogical knowledge and engineering content expertise to create engineering experiences that were developmentally appropriate for high school participants. These experiences positively impacted teacher participants' attitudes towards engineering, revealing the benefits of collaborative efforts between K-12 educators, student participants and engineering professionals.

Because of the positive feedback from the teachers regarding the combination of a studentfocused engineering summer camp with a teacher professional development program, this model of teacher professional learning could be adopted at other universities with a likelihood of similarly positive results. While the focus on the SEPs and the Standards during the evening professional development workshop portions of the camp are important for helping the teachers to be able to teach engineering in their own classes, the main point of embedding the teacher professional learning is to allow the teachers to see the science and engineering practices being applied with students present.

\section{Future Work}

For future camps the researchers and the engineering faculty will implement some of the changes that were suggested by the teachers. The professional learning workshops for future camps will include more time for the teachers to collaborate with each other to create lesson plans. There will also be time for them to discuss things that have worked or not worked for them in their classrooms. The researchers will also work with the engineering faculty to make sure that the engineering experiences are hands-on and include data analysis that the students and teachers are capable of doing in the allotted time. 


\section{References}

[1] Utah State Board of Education. (2019). Utah Science with Engineering Education (SEEd) Standards.

[2] National Research Council, Committee on a Conceptual Framework for New K-12 Science Education Standards, Board on Science Education, Division of Behavioral and Social Sciences and Education. 2012. "A Framework for K-12 Science Education: Practices, Crosscutting Concepts, and Core Ideas." Washington, DC: National Academies Press.

[3] S. Boesdorfer and K. Staude, "Teachers' Practices in High School Chemistry Just Prior to the Adoption of the Next Generation Science Standards," School Science and Mathematics, vol. 116, no. 8, pp. 442-458, Dec. 2016.

[4] R. Ames, "A Survey of Utah's Public Secondary Education Science Teachers to Determine Their Preparedness to Teach Engineering Design," Master's Thesis, Dept. of Engineering and Technology Education, Utah State University, Logan, UT, 2014.

[5] H. Johnson and M. Cotterman, "Collaborative Efforts to Put the 'E' Back in STEM," Nations Science Teachers Association Reports, vol. 55, no. 4, pp. 3-32, Nov. 2013.

[6] R. Bybee, "NGSS and the Next Generation of Science Teachers," Journal of Science Teacher Education, vol. 25, no. 2, pp. 211-221, Mar. 2014.

[7] N. Lederman and J. Lederman, "Next Generation Science Teacher Educators," Journal of Science Teacher Education, vol. 24, no. 6, pp. 929-932, Sep. 2013.

[8] S. Ambrose, M. Bridges, M. DiPietro, M. Lovett, and M. Norman, How Learning Works: Seven Research-Based Principles for Smart Teaching. San Francisco, CA: John Wiley \& Sons, 2010.

[9] E. Banilower, P. Smith, I. Weiss, K. Malzahn, K. Campbell, and A. Weis, Report of the 2012 National Survey of Science and Mathematics Education. Chapel Hill, NC: Horizon Research, Inc, 2013.

[10] Ghosh, S., \& Jayasree Krishnan, V., \& Borges Rajguru, S., \& Kapila, V. (2019, June), Middle School Teacher Professional Development in Creating a NGSS-plus-5E Robotics Curriculum (Fundamental) Paper presented at 2019 ASEE Annual Conference \& Exposition, Tampa, Florida. https://peer.asee.org/33108

[11] Lakin, J. M., \& Ewald, M. L., \& Blanco, N. N., \& Gilpin, J. A. (2019, June), Work in Progress: Impact of Teaching Engineering Summer Academy on Teacher Efficacy and Teaching Beliefs Paper presented at 2019 ASEE Annual Conference \& Exposition , Tampa, Florida. https://peer.asee.org/32202 
[12] Thomas, S. W., \& Campbell, S. W., \& Devisetty Subramanyam, M., \& Ellerbrock, C. R. (2019, June), Contemporary STEM Issues: Engineering Training of Pre-Service Teachers for Middle School STEM Curriculum Development (Evaluation) Paper presented at 2019 ASEE Annual Conference \& Exposition, Tampa, Florida. https://peer.asee.org/32545

[13] Krishnamoorthy, S. P., \& Borges Rajguru, S., \& Kapila, V. (2019, June), Designing NGSS-Aligned Lesson Plans During a Teacher Professional Development Program (Fundamental) Paper presented at 2019 ASEE Annual Conference \& Exposition, Tampa, Florida. https://peer.asee.org/32621

[14] Lavelle, J. P., \& Bottomley, L., \& Kendall, A. L. M., \& Stimpson, M. T. (2019, June), An Engineering Grand Challenge-focused Research Experience for Teachers (RET) Program: Purpose, Outcomes, and Evaluation (Evaluation) Paper presented at 2019 ASEE Annual Conference \& Exposition, Tampa, Florida.

https://peer.asee.org/32059

[15] Smith, J. D., \& Lohani, V. K. (2019, June), An Interdisciplinary RET Program: Assessment with Concerns-Based Adoption Model (RTP) Paper presented at 2019 ASEE Annual Conference \& Exposition, Tampa, Florida. https://peer.asee.org/32075

[16] Veety, E. N., \& Lamberth, J. E., \& Baldwin, E. L. (2019, June), Impact of Authentic, Mentored Research Experiences for Teachers on Pedagogy (Fundamental) Paper presented at 2019 ASEE Annual Conference \& Exposition, Tampa, Florida. https://peer.asee.org/32923

[17] Yilmaz, M., Ren, J., Custer, S., \& Coleman, J. (2010). Hands-on Summer Camp to Attract K-12 Students to Engineering Fields. IEEE Transactions on Education, 53(1), $144-151$.

[18] Hammack, R., Ivey, T. A., Utley, J., \& High, K. A. (2015). Effect of an Engineering Camp on Students' Perceptions of Engineering and Technology. Journal of PreCollege Engineering Education Research, 5(2), 10-21.

[19] Mahmoud, M. M., \& Becker, K. H., \& Longhurst, M. L., \& Dupont, R. R., \& Mesner, N., \& Dorward, J. (2018, June), Factors Influencing the Interest Level of Secondary Students going into STEM fields and their parents' perceived interest in STEM (Evaluation) Paper presented at 2018 ASEE Annual Conference \& Exposition, Salt Lake City, Utah. https://peer.asee.org/30507

[20] Mahmoud, M. M., \& Becker, K. H., \& Longhurst, M. L. (2017, June), Hands-on Summer Workshop to Attract Middle School Students to Engineering (Work in Progress) Paper presented at 2017 ASEE Annual Conference \& Exposition, Columbus, Ohio. https://peer.asee.org/27671 
[21] Singh, M. N. K., \& Francis, K., \& Sather, J. A. P., \& Egberts, P. (2019, June), Designing and Implementing a Transdisciplinary Engineering Camp (Evaluation, Diversity) Paper presented at 2019 ASEE Annual Conference \& Exposition, Tampa, Florida. https://peer.asee.org/32618

[22] "Engineering Design Process," Teach Engineering, University of Colorado Boulder. Accessed on: June 28, 2019. Available:

https://www.teachengineering.org/k12engineering/designprocess

[23] Saldana, J. (2016). The Coding manual for Qualitative Researchers $-3^{\text {rd }}$ ed. Thousand Oaks, CA: SAGE Publications, Inc. 


\section{Appendix A}

GEAR UP 2 Lesson Plan Evaluation Protocol (Completed by Researcher)

\section{School:}

Teacher:

Years of Teaching:
Date: Grade/Subject:

\section{Contextual Background}

A brief description of the lesson and any other important details about the teacher or the class.

\section{$\underline{\text { Ratings }}$}

How well has the teacher applied the Science and Engineering Practices in this lesson? (practices specific to engineering are underlined)

$(0=$ Not present in lesson, $1=$ negligible application, $2=$ limited application, $3=$ moderate application, 4 = significant application)

1. Asking questions and defining problems

2. Developing and using models 
3. Planning and carrying out investigations

4. Analyzing and interpreting data

$\begin{array}{llll}0 & 1 & 2 & 3\end{array}$

4

5. Using mathematics and computational thinking

$\begin{array}{llll}0 & 1 & 2 & 3\end{array}$ 4

6. Constructing explanations and designing solutions

$\begin{array}{llll}0 & 1 & 2 & 3\end{array}$ 4

7. Engaging in argument from evidence

$\begin{array}{llll}0 & 1 & 2 & 3\end{array}$

4

8. Obtaining, evaluating, and communicating information

$\begin{array}{llll}0 & 1 & 2 & 3\end{array}$ 4

\section{$\underline{\text { Rationale for Ratings }}$}

A brief description of the reasons for the ratings above. 


\section{Appendix B}

GEAR UP 2 Observation Protocol (Completed by Researcher)

School:

Teacher:

Years of Teaching:
Date: Grade/Subject:

\section{Contextual Background}

A brief description of the lesson, the classroom setting, and any other important details about the teacher or the classroom.

\section{$\underline{\text { Ratings }}$}

How well has the teacher applied the Science and Engineering Practices in this lesson? (practices specific to engineering are underlined)

$(0=$ Not present in lesson, $1=$ negligible application, $2=$ limited application, $3=$ moderate application, 4 = significant application)

1. Asking questions and defining problems 
3. Planning and carrying out investigations

$\begin{array}{llll}0 & 1 & 2 & 3\end{array}$ 4

4. Analyzing and interpreting data

$\begin{array}{llll}0 & 1 & 2 & 3\end{array}$ 4

5. Using mathematics and computational thinking

$\begin{array}{llll}0 & 1 & 2 & 3\end{array}$ 4

6. Constructing explanations and designing solutions

$\begin{array}{llll}0 & 1 & 2 & 3\end{array}$ 4

7. Engaging in argument from evidence

$\begin{array}{llll}0 & 1 & 2 & 3\end{array}$ 4

8. Obtaining, evaluating, and communicating information

$\begin{array}{llll}0 & 1 & 2 & 3\end{array}$ 4

\section{Description of Events}

